
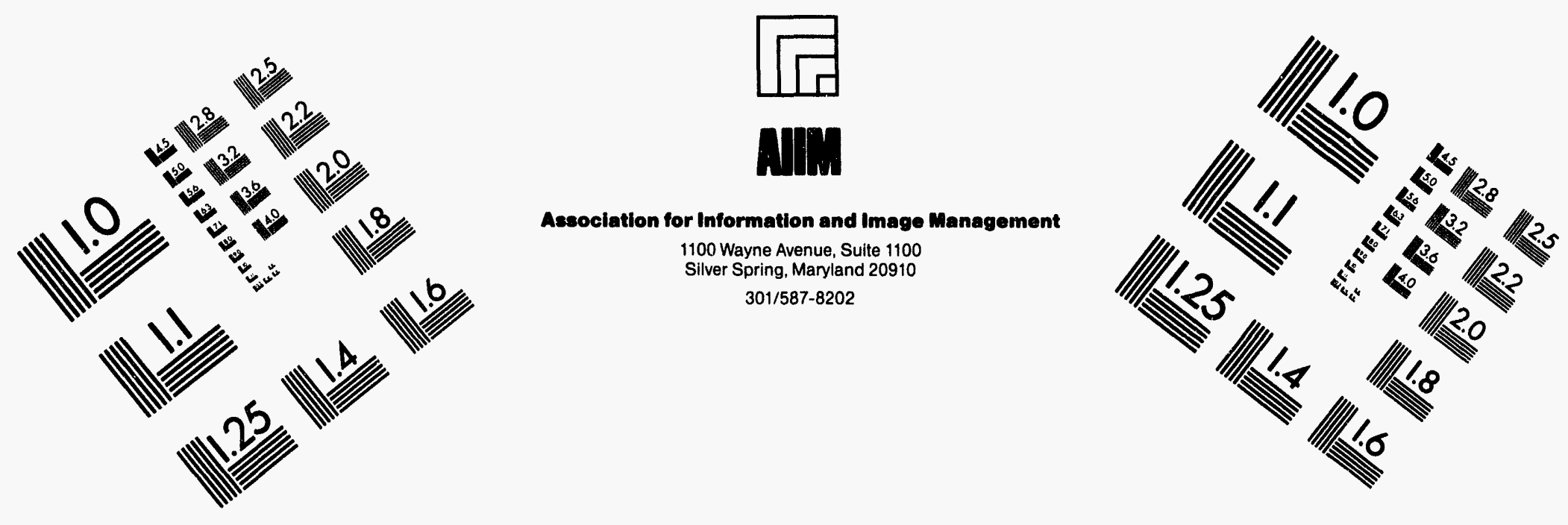

\title{
Centimeter
}

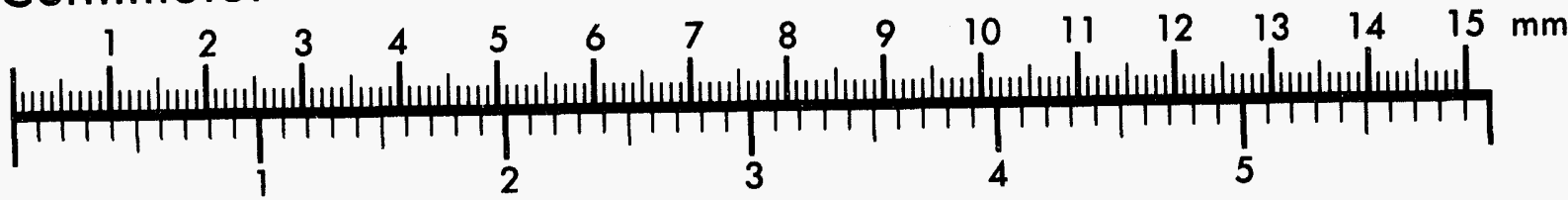
Inches
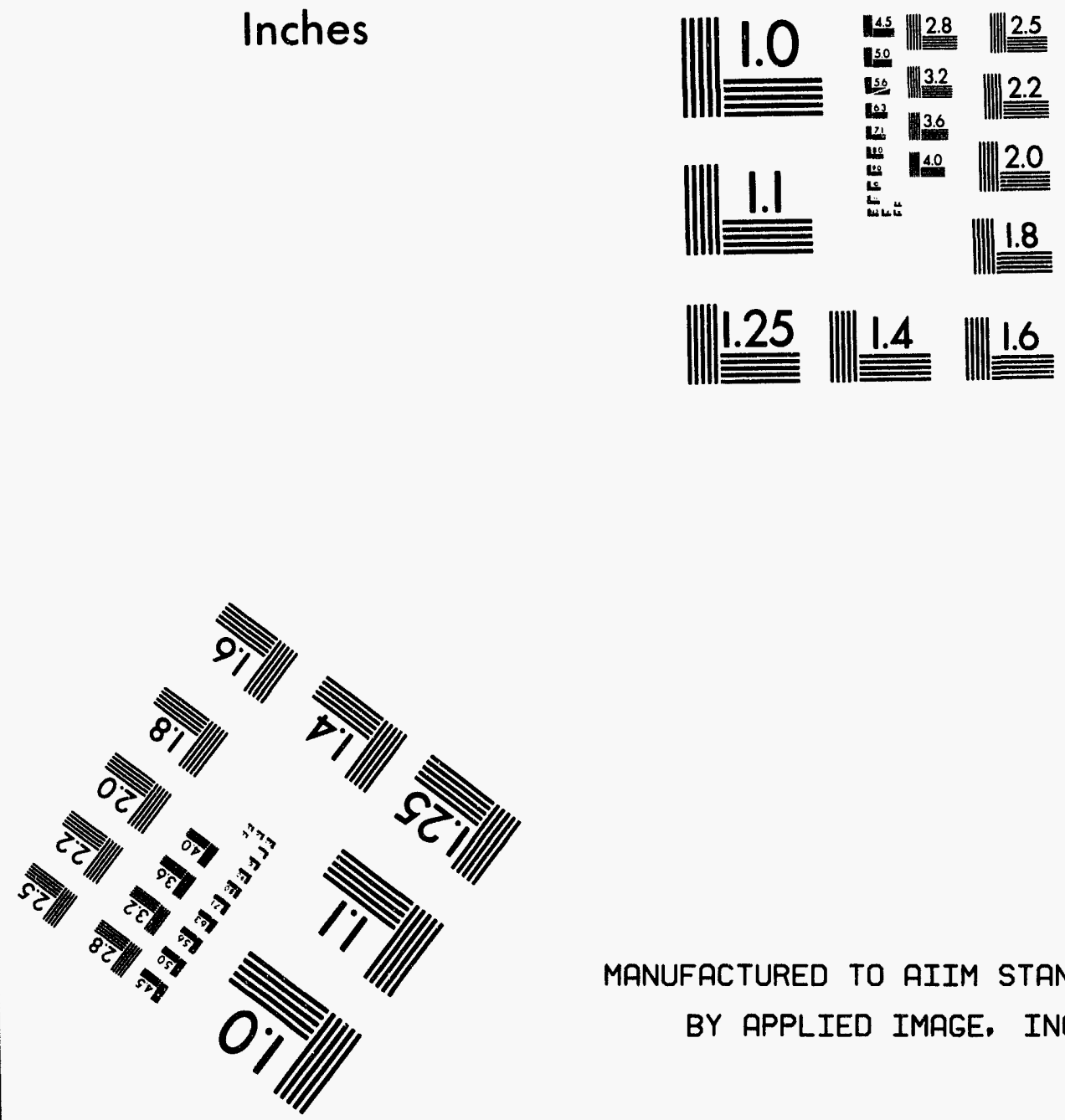

MANUFACTURED TO AIIM STANDARDS

BY APPLIED IMAGE, INC.

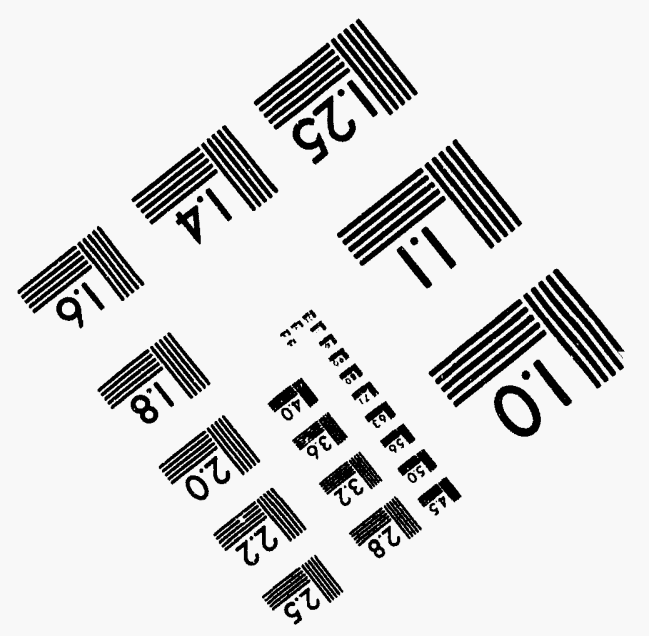



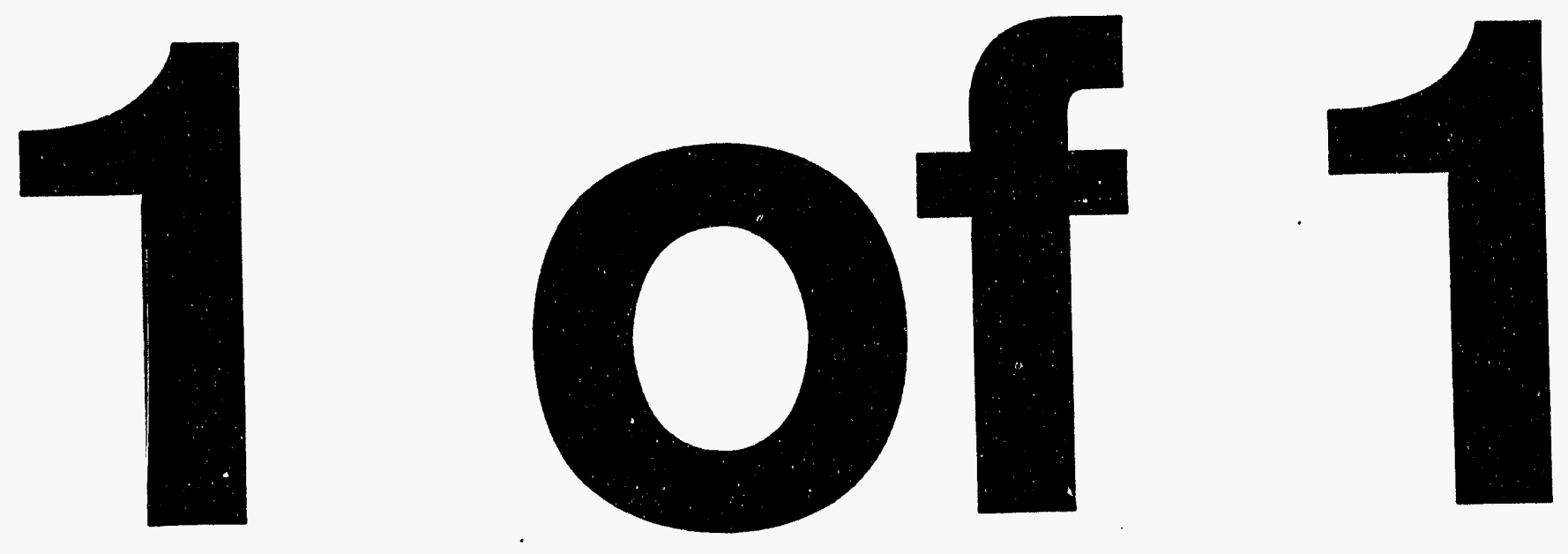


\title{
An Overview of PBX-M H-Mode Results
}

S.M. Kaye, H. Kugel, B. LeBlanc, S. Sesnic and the PBX-M Group (Princeton Plasma Physics Laboratory, Princeton University, P.O. Box 451, Princeton, N.J., 08543, U.S.A), J.L. Dunlap and the ORNL Group (ORNL, Oak Ridge, Tn., 37831), L. Schmitz, G. Tynan, and the UCLA Group (IPFR, UCLA, L.A., Cal. 90024, U.S.A)

\begin{abstract}
PBX-M is a tokamak operated with indented plasmas, a close-fitting conducting shell, and various RF systems in order to study the physics of current and pressure profile control, and ease the access to the second stability regime. In addition to these uncommon and unique features, PBX-M, because of its divertor operation, has also proved to be a valuable contributor to identifying and understanding various features of $\mathrm{H}$-mode physics. Time stationary H-modes $\left(t>\tau_{E}\right)$ at high power $(\sim 5 \mathrm{MW})$ have been obtained, and these discharges have attained $\beta_{\mathrm{t}} /(\mathrm{I} / \mathrm{aB})$ values of 4.5 simultaneously with $\tau_{\mathrm{E}} / \tau_{\mathrm{E}}$ ITER$89 \mathrm{P}$ values of up to 3.5 . In this paper, results of recent $\mathrm{H}$-mode studies will be presented. These studies focused on specific aspects of $\mathrm{H}$-mode physics. To be reported here are results of studies of bias induced $\mathrm{H}$-modes, $\mathrm{L}$ - to $\mathrm{H}$ - transitions, including the suppression of turbulent transport, ELMs and other related energy loss mechanisms, and, finally, Ion Bernstein Wave modification of $\mathrm{H}$-mode discharges.
\end{abstract}




\section{An Overview of PBX-M H-Mode Results}

S.M. Kaye, H. Kugel, B. LeBlanc, S. Sesnic and the PBX-M Group (Princeton Plasma Physics Laboratory, Princeton University, P.O. Box 451, Princeton, N.J., 08543, U.S.A), J.L. Dunlap and the ORNL. Group (ORNL, Oak Ridge, Tn., 37831), L. Schmitz, G. Tynan, and the UCLA Group (IPFR, UCLA, L.A., Cal. 90024, U.S.A)

\section{Introduction}

PBX-M is a tokamak operated with indented plasmas, a close-fitting conducting shell, and various RF systems in order to study the physics of current and pressure profile control, and ease the access to the second stability regime. In addition to these uncommon and unique features, PBX-M, because of its divertor operation, has also proved to be a valuable contributor to identifying and understanding various features of $\mathrm{H}$-mode physics [1-6]. Time stationary $\mathrm{H}$-modes $\left(\mathrm{t}>\tau_{\mathrm{E}}\right)$ at high power $(\sim 5 \mathrm{MW})$ have been obtained, and these discharges have attained $\beta_{\mathrm{t}} /(\mathrm{I} / \mathrm{aB})$ values of 4.5 simultaneously with $\tau_{\mathrm{E}} / \tau_{\mathrm{E}}$ ITER-89P values of up to 3.5. The large H-mode confinement values relative to $\tau_{\mathrm{E}}{ }^{\text {ITER-8}} \mathrm{H} \%$ are in part due to enhanced L-mode confinement (relative to $\tau_{\mathrm{E}}{ }^{\mathrm{TTER}-89 \mathrm{P}}$ ); the enhanced L-mode is most likely due to the large aspect ratio of PBX-M $(R / a=5.5)$ either on its own or in combination with the high triangularity associated with indentation.

In this paper, results of recent $\mathrm{H}$-mode studies will be presented. These studies focused on specific aspects of $\mathrm{H}$-mode physics. To be reported here are results of studies of bias induced $\mathrm{H}$-modes, $\mathrm{L}$ - to $\mathrm{H}$ - transitions, including the suppression of turbulent transport, ELMs and other related energy loss mechanisms, and, finally, Ion Bernstein Wave modification of $\mathrm{H}$-mode discharges. The $\mathrm{H}$-mode experiments, as well as all the other experiments, on PBX-M have enjoyed major contributions by collaborative groups at ORNL, UCLA, MIT, and CIEMAT.

\section{Passive Plate Bias}

Edge biasing is used as a means of controlling the poloidally asymmetric particle and heat loss and inducing impurity flow into the divertor region by applying a cross-plasma potential drop. The PBX-M double-null divertor geometry, with its electrically-isolated close-fitting passive plates, makes it ideally qualified to test a unique scheme of biasing the outside edge of the plasma with respect to the inside edge [7]. A biasing experiment was performed to test the effect of bias voltage on the $\mathrm{H}$-mode transition power threshold. Plasma parameters for this study were $I_{p}=250 \mathrm{kA}$, line averaged $n_{e}=4 \times 10^{13} \mathrm{~cm}^{-3}, B_{T}=1.5$ $T$ and $D^{\circ}$ neutral beam injection (NBI) into $D^{+}$plasmas. Fig. 1 shows the results of the study. With no biasing, the $\mathrm{H}$-mode threshold was $>2.2 \mathrm{MW}$ of NBI. A positive bias voltage of at least $25 \mathrm{~V}$ was needed to cause a reduction in the required transition power; above this voltage, the $\mathrm{H}$-mode threshold power was reduced by approximately $30 \%$, to a value of $1.5 \mathrm{MW}$, consistent with the prediction from the multi-machine power threshold scaling [8]. The typical bias current was 20 to $60 \mathrm{~A}$. Bias and non-bias discharges were interlaced in order to eliminate any systematic change of wall or discharge condition as a cause for this reduction in power threshold. Future experiments will investigate the effect of negative bias.

\section{L-H Transition}

In PBX-M, L- to H-mode transitions were usually induced by sawteeth, with approximately a $5 \mathrm{msec}$ time delay between the sawtooth crash and the decrease in $\mathrm{D}_{\alpha}$ which indicated the transition. This delay time is usually interpreted to be the time required for the sawtooth heat pulse to reach the edge of the plasma, and is consistent with an edge L-mode diffusivity of 5 to $10 \mathrm{~m}^{2} / \mathrm{sec}$. One interesting question that has been raised about this sequence of events is whether the sawtooth preceding the transition is, in 


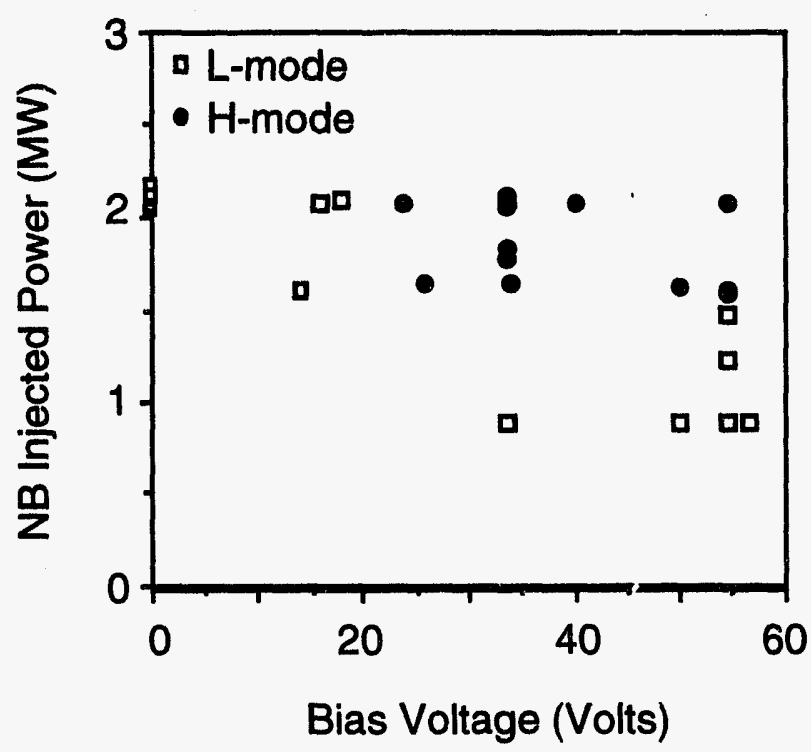

Fig. 1 Effect of $m=1$ bias voltage on H-mode power threshold any way, different from those that do not lead to transitions. One indication of such a difference might be in the behavior of the magnetic fluctuations near the edge of the plasma.

To look for such differences in the fluctuations, we have used data from the midplane toroidal array of Mirnov coils. This array consists of ten coils on the outside midplane and five coils on the inside midplane. For this study, seven of the outside and all five of the inside coils were connected to LeCroy 6810 digitizers with enough memory to allow acquisition of 256 msec of data at a sampling rate of 1 $\mathrm{MHz}$. Auto power spectral densities (APSD) of individual Mirnov signals were computed for a four msec time interval occurring after the transitioninducing sawtooth (but before the transition), and for a corresponding four msec time interval just after the preceding L-phase sawtooth. The APSD is $\propto \tilde{B}^{2}$, where $\tilde{B}$ is the amplitude of the fluctuating magnetic field. The ratios of the APSDs for these two four msec intervals for several of the outer midplane coils are shown in Fig. 2. The signal ratios essentially overlay, indicating little toroidal variation, and the ratios are approximately 1 over

the entire frequency

range from 0 to 500

$\mathrm{kHz}$, indicating no

significant difference between the two sawteeth, with respect to the postcursor magnetic fluctuation activity. Another feature which has been studied with this set of Mirnov coils is the change in fluctuation level going from the L- to the $\mathrm{H}$ phase. Similar to the comparison shown in the previous discussion, Fig. 3 shows ratios of the APSDs for two intervals, one early in the H-phase (just after the transition), and the

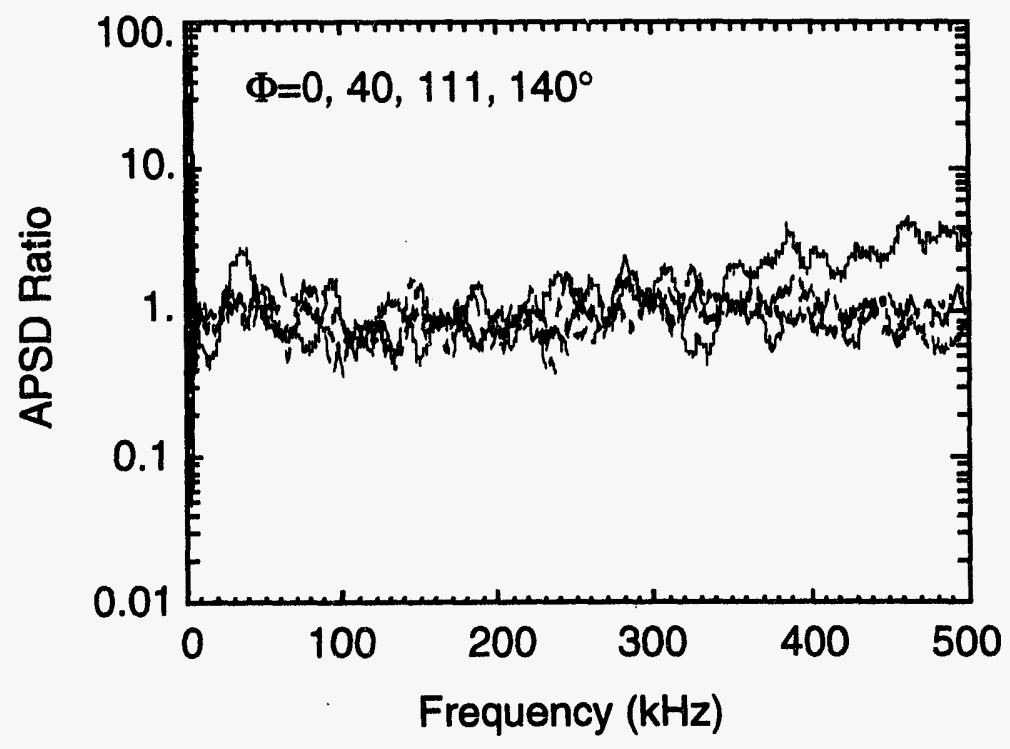

Fig. 2 APSD ratios of four outer midplane Mirnov coils. The ratios are of time intervals after sawtooth crashes of the pre-transition sawtooth to the preceding L-phase sawtooth. other late in the $\mathrm{L}$ phase, corresponding to the time interval after the transition-inducing sawtooth but prior to the transition. Signal ratios are overlaid for three different discharges using coils from the outside midplane (Fig. 3a) and inside midplane (Fig. 3b). As the figure shows, the signal amplitudes generally decreased for all frequencies going from the L- to the $\mathrm{H}$ - 

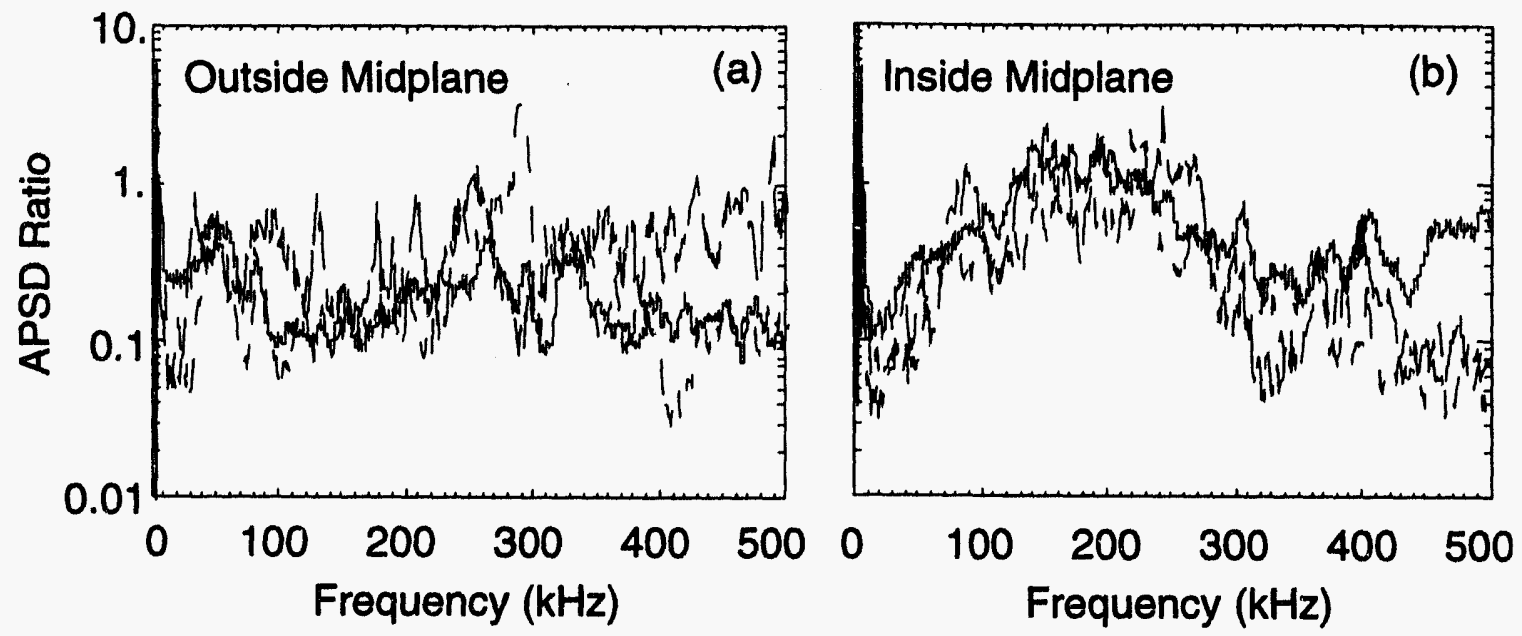

Fig. 3 APSD Ratios of outside (a) and inside (b) coils for L- to H-transition for three different discharges. The ratios are of magnetic fluctuation levels just after the transition to just before the transition.

phase. The figure also shows, however, that the effect was not uniform for all frequencies, and there was variation from discharge-to-discharge, despite the discharges being otherwise similar. Additionally, the inner coils consistently showed only a small reduction in the fluctuation level in the frequency range from $\sim 100$ to $275 \mathrm{kHz}$, indicating systematic differences in the evolution of the magnetic fluctuations between the inside and outside midplane. The significance of these differences is presently under study.

The change in fluctuation levels internal to the plasma was studied using the vertical soft X-ray (SXR) diode array. It was found that the normalized fluctuation amplitude (the fluctuation amplitude normalized to the average local emissivity) exhibited a factor of two to ten decrease in amplitude going from L- to H-phase over the frequency range from 0 to $100 \mathrm{kHz}$.

The measurement of the changes in the DC electric field and turbulent transport in the velocity shear region of a spontaneous $\mathrm{H}$-mode was made possible by use of the UCLA fast reciprocating probe [9]. The probe mechanism is composed of multiple probe tips which are used to measure the electron density, temperature, and plasma potential. $\mathrm{E}_{\theta}$ is determined by differences in the measured potential between two probes separated poloidally, while $E_{r}$ is determined from radial differences in the potential. A double probe and a probe measuring the ion saturation current are used to determine $T_{e}$ and $n_{e}$. The time averaged turbulent flux, $\Gamma_{\mathrm{r}}$, is determined from the correlation between the fluctuating density and $E_{\theta}$. Standard techniques are used to calculate the various spectral characteristics (power, wave number, and wave group and phase velocities) of the fluctuations, in a bandwidth from 0 to $500 \mathrm{kHz}$.

The probe has a maximum insertion speed of $3.5 \mathrm{~m} / \mathrm{sec}$, with a typical dwell time at its point of maximum insertion of 10 to $25 \mathrm{msec}$. This gives a total data collection time of $\sim 100$ msec. Maximum insertion is just inside the Last Closed Flux Surface.

The evolution of the edge properties through an L- to H-mode transition is shown in Fig. 4. The top two traces, which are the line integrated soft X-ray emissivity through the center of the plasma and outside the inversion radius, exhibited a sawtooth crash leading to an L- to $\mathrm{H}$-transition at $475.1 \mathrm{msec}$. The floating potential exhibited the $\mathrm{m}=1 / \mathrm{n}=1$ sawtooth precursor. Both the plasma potential and the ion saturation current increased at the time of the crash, as did the turbulent flux. The actual transition occurred at $475.8 \mathrm{msec}$, at which time the fluctuation amplitude of the ion saturation current and floating potential decreased, resulting in a decrease in the turbulent flux.

The edge density profile and radial electric field exhibited the usual evolution 


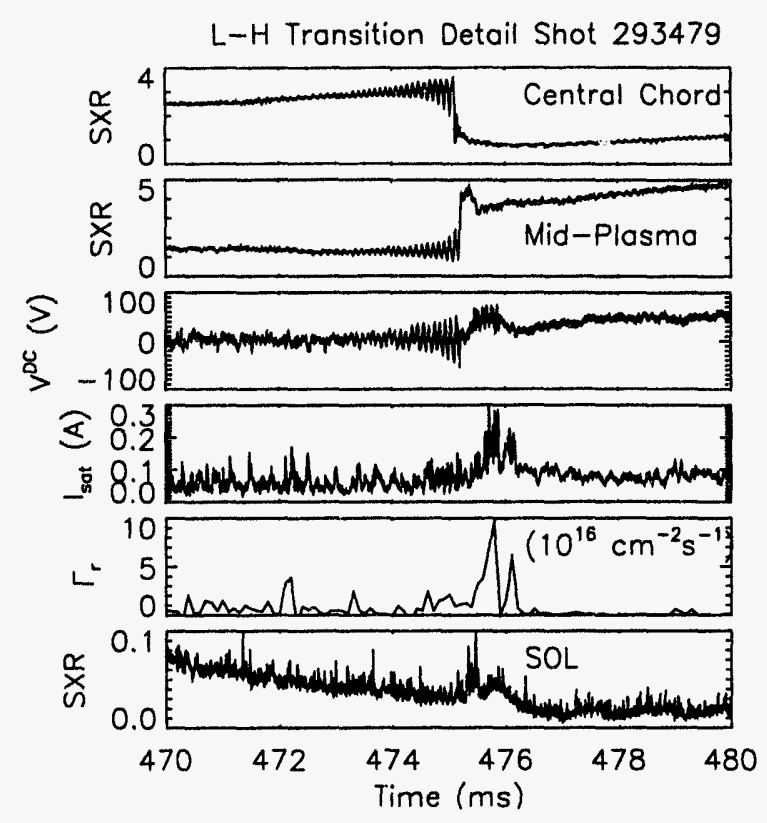

Fig. 4 An overview of details of the L-H transition. from the L- to the H-phase. A shallow edge density gradient during the L-phase steepened during the $\mathrm{H}$-phase as the edge density increased. The DC radial electric field during the $\mathrm{L}$-phase was $3.5 \mathrm{kV} / \mathrm{m}$ directed outward; however, during the $\mathrm{H}$-phase the radial electric field was directed radially inward with a magnitude of $12 \mathrm{kV} / \mathrm{m}$, consistent with values measured in DIII-D and elsewhere [10]. The region of largest DC radial electric field and strongest density gradient was at the separatrix.

Figure 5 shows the comparison of the turbulent flux and particle diffusivity $\left(=\Gamma_{\mathrm{r}} / \nabla \mathrm{n}_{\mathrm{e}}\right)$ between the two discharge phases. The turbulent particle flux (top panel) during the H-phase was lower by up to

a factor of four relative to that during the L-phase from the region of strong negative radial electric field outward. This reduction in particle flux is the reason for the build up of the density and development of the strong density gradient in this region during the $\mathrm{H}$-phase. The reduction in turbulent flux and the increase in density gradient yielded more than one order of magnitude decrease in the particle diffusivity going from Lto $\mathrm{H}$-phase (bottom panel). The new observation here is the reduction of turbulent particle flux not only in the separatrix region, but extending into the scrape-off layer as well.

The reduction in the turbulent transport was due to several factors. At the transition, the density fluctuation amplitude decreased by about $40 \%$ both in the separatrix region and in the scrape-off layer. During the $\mathrm{H}$ phase, the density fluctuation amplitude in the scrape-off

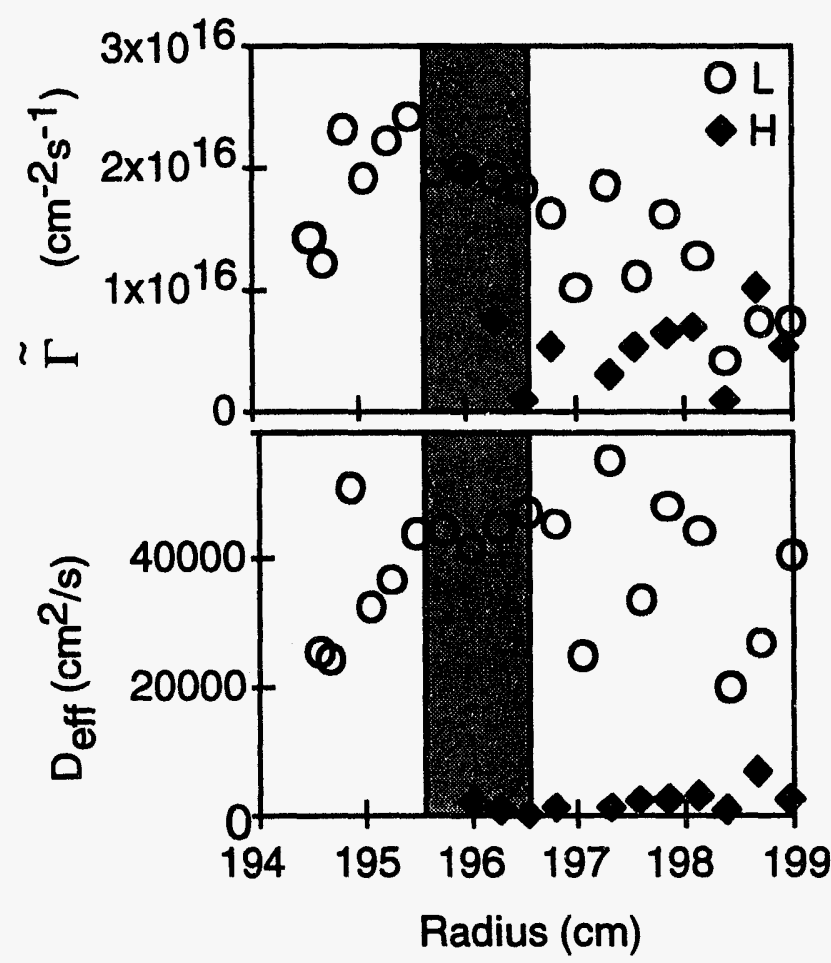

Fig. 5 Turbulent flux (top) and particle diffusivity (bottom) as determined from fast probe. The grey shaded area represents the separatrix region. recovered to its $L$-phase value while that in the separatrix region remained lower. The 
potential fluctuation in the separatrix region was also reduced during the $\mathrm{H}$-phase by about $20 \%$. Furthermore, during the $\mathrm{H}$-phase, there was a narrowing in $\mathrm{k}_{\theta}$ of the power spectral density, with a reduction in the characteristic $\mathrm{k}_{\boldsymbol{\theta}}$ of the fluctuations. Lastly, there was a 60 to $80 \%$ reduction in the correlation between the density and potential fluctuations in the separatrix region. The key result is that the reduction in fluctuation amplitude was modest, and does not solely explain the reduction in turbulent transport; the other effects just mentioned are not only necessary, but may, in fact, be dominant. The observations are consistent in general with the shear stabilization theory [11], although details of the observations (e.g., the radial extent of the turbulent flux suppression and the detailed behavior of the density and potential fluctuations) indicate that a more refined theory is needed [9].

\section{ELMs and ETPs}

While Edge Localized Modes (ELMs) can be deleterious to the confinement of $\mathrm{H}$ mode plasmas, causing both energy and particle losses, they can also play a positive role by controlling impurity levels and leading to near steady-state discharge conditions with relatively low radiative power losses [12-14], with a relatively small reduction in energy confinement time[15]. The importance of ELMs has led to numerous studies which attempt to uncover their nature, although the results of these studies are mixed and underscore the complexity of the events [ 6 and references therein]. The recent study of ELMs on PBX-M utilized the fast Mirnov coil data acquisition system described earlier. Typical discharges studied had $\mathrm{I}_{\mathrm{p}}=280 \mathrm{kA}, \mathrm{B}_{\mathrm{T}}=1.3 \mathrm{~T}$, and $2.2 \mathrm{MW}$ of $\mathrm{D}^{\circ}$ injection into $D^{+}$plasmas, with $\beta_{\text {pol }} 1$ and $\beta_{t}(\mathrm{I} / \mathrm{aB})=1$. Techniques used for this study employ standard spectral analysis to determine cross-power, cross-coherence, and cross-phase of signals
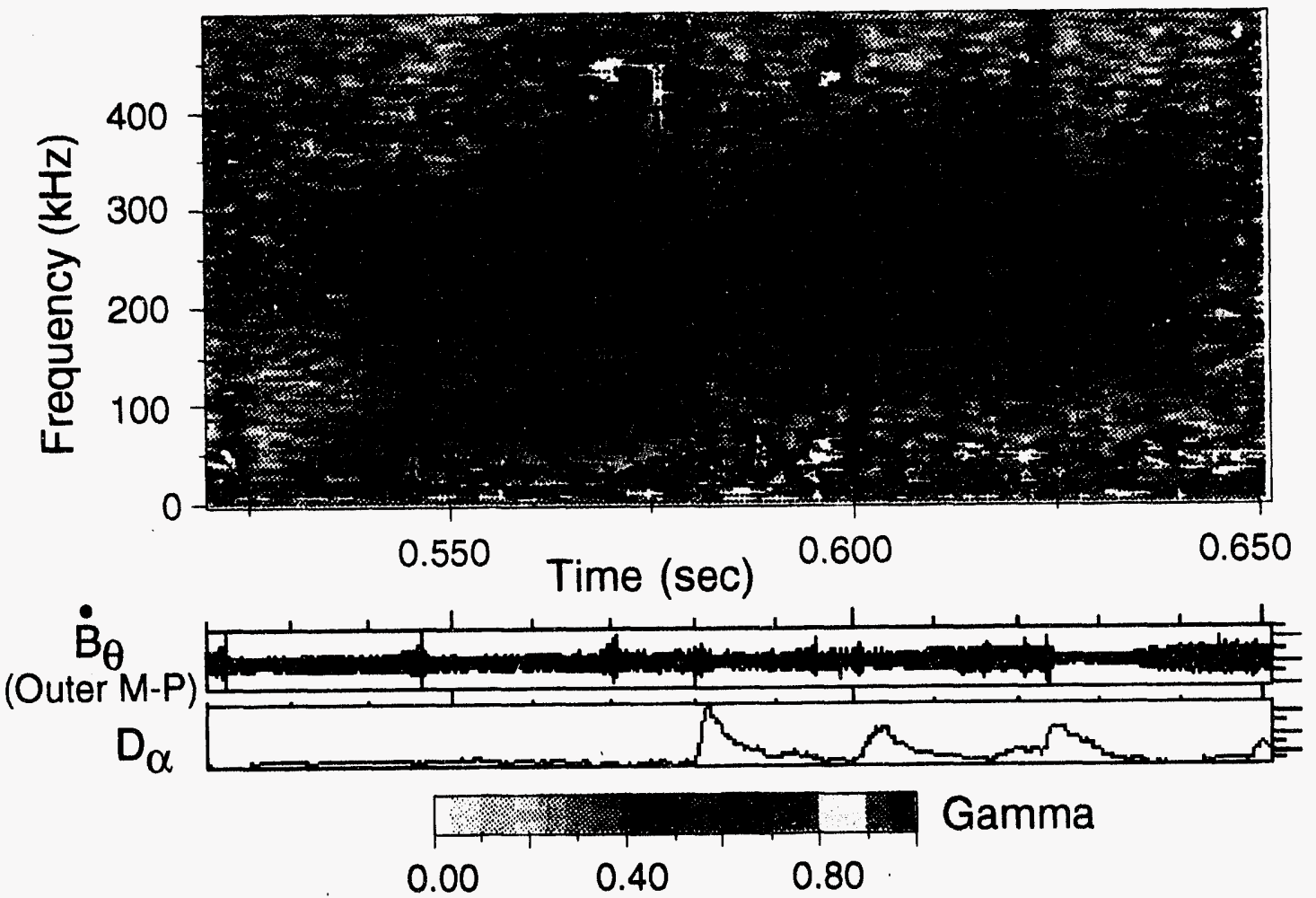

Fig. 6 Cross-coherence of a pair of outer midplane Mirnov coils separated toroidally by $41^{\circ}$ 
from pairs of Mirnov coils. The cross-power reflects the spectral power common to two fluctuating signals, the cross-coherence reflects the degree of correlation of the two signals, and the cross-phase indicates the phase difference between the two.

A color contour plot of the cross-coherence between two coils situated on the outer midplane and separated toroidally by $41^{\circ}$ is shown in Fig. 6 . Below the contour plot are time traces of one of the Mirnov signals and the $D_{\alpha}$ emission. The contour plot highlights cross-coherence values $\geq 0.7$. At the start of the data acquisition $(520 \mathrm{msec})$, the discharge had been in an ELM-free phase for over $70 \mathrm{msec}$. ELMs appeared at $580 \mathrm{msec}$. The two main features associated with the ELM of $580 \mathrm{msec}$ are 1) an increase in crosscoherence at high frequency ( $\geq 250 \mathrm{kHz}$ ) several msec prior to the $\mathrm{D}_{\alpha}$ increase, and 2) a decrease in cross-coherence in this high frequency range and the start of intense, coherent activity near $200 \mathrm{kHz}$ coincident with the increase in $\mathrm{D}_{\alpha}$. These two features recur from ELM-to-ELM, as well as from discharge-to-discharge, although some variation was seen in the evolution of the pre- $\mathrm{D}_{\alpha}$ rise activity [6].

More detailed information about the mode structures of the activity can be obtained by comparing the cross-power and cross-coherence of coils at various toroidal and poloidal separations. This comparison is shown in Fig. 7. for two pairs of coils, each pair separated toroidally by $70^{\circ}$ with one pair on the inside and the other pair on the outside midplane. Fig. 7a shows the comparison for the period just prior to the $D_{\alpha}$ increase, and $7 \mathrm{~b}$ shows that for the period after the $D_{\alpha}$ increase. For the earlier period, both the inside and outside coil pairs exhibited a broad peak in power for frequencies
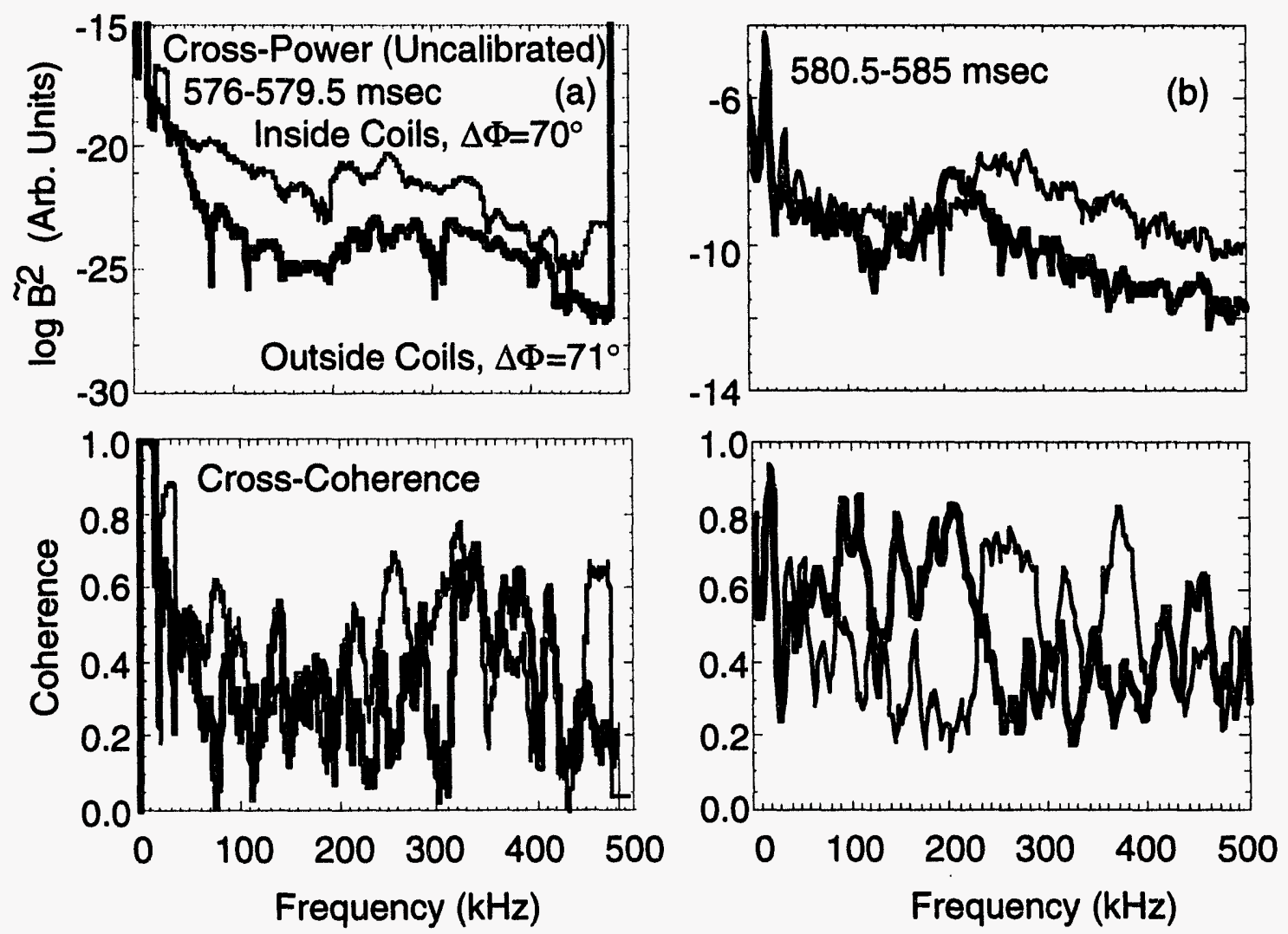

Fig. 7. Cross-power and coherence for Mirnov coil pairs before (a) and after (b) the rise in $\mathrm{D}_{\alpha}$. 
$\geq 250 \mathrm{kHz}$. Distinct peaks were seen in the power and coherence for both coil pairs, but the peaks had no unambiguous identifiable mode structure.

For the later time period, however, clear differences between the inside and the outside coil pairs could be discerned. A peak in power and coherence was seen in the frequency range from $\sim 150$ to $250 \mathrm{kHz}$ on the outside coils. This activity was extended toroidally, and it was composed of a series of harmonic peaks whose toroidal mode numbers ranged from $n=3$ to 8 . The frequency dependence of the observed harmonic structure could be described by the relation $f_{n}=f_{0}+n \Delta f$, where $f_{0}=30$ to $50 \mathrm{kHz}$ and $\Delta f=20$ to $30 \mathrm{kHz}$. On the inside, both the power and especially the coherence were reduced at these lower frequencies. This, and the lack of any identifiable harmonic mode structure similar to that on the outside, indicates an outward ballooning character of this low to medium- $n$ activity. A candidate to explain this outward ballooning feature is the kinetic ballooning mode $[16,17]$ whose eigenfrequency is the fast ion bounce frequency Doppler shifted by $\vec{k} \times \vec{v}_{E}, \vec{v}_{E}$ being dominated by the poloidal rotation velocity driven by an inward directed radial electric field $[6,9]$.

ETPs, or Enhanced Transport Periods, are similar to ELMs, but they are of much longer duration ( $\leq 20 \mathrm{msec}$ as compared to the $0.5 \mathrm{msec}$ duration of a large ELM). ETPs are observed in discharges approaching the $\beta$-limit, and are characterized by significant energy losses from the confinement region of the plasma which can lead to a factor of $50 \%$ reduction in energy confinement time [18]. Similar to ELMs, ETPs can be (partially) responsible for a $\beta$-collapse, they can be initiated by a sawtooth with a several msec time delay, and they can cause increases in the $D_{\alpha}$ emission, the increases lasting for the duration of the ETP. One major difference between ETPs and large ELMs is that while the energy loss in both cases is maximum in the confinement region of the discharge, the energy loss associated with the ELM penetrates to near the plasma center, while that associated with the ETP is limited to the confinement region, and the maximum loss is slightly farther inside. The temporal sequence between the sawtooth and the ETP (as well as large ELM) suggests that the sawtooth transports energy from the core of the

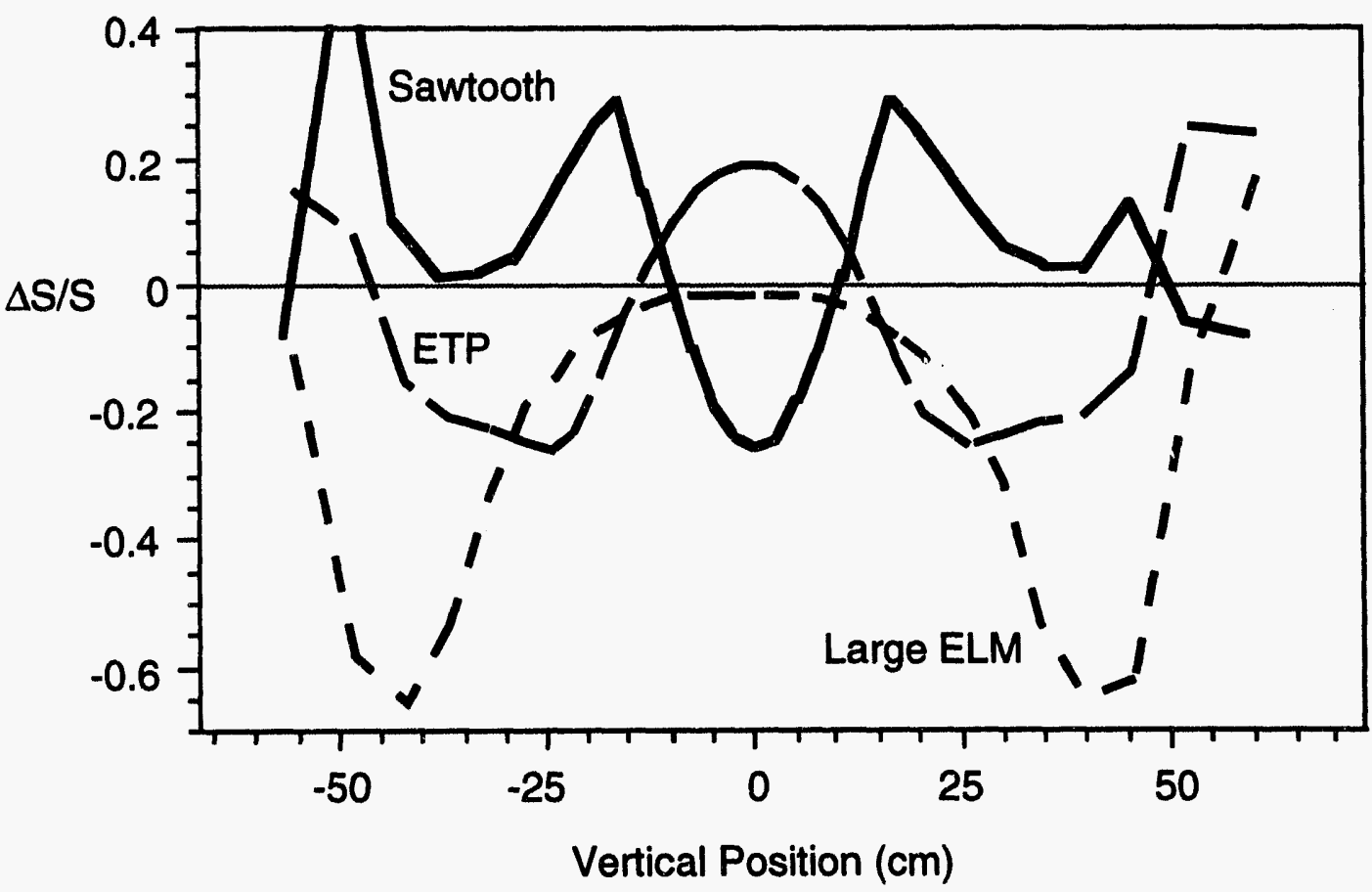

Fig. 8 Comparison of relative change in SXR signal through sawtooth (solid) large ELM (short dash) and ETP (long dash) events. 
plasma to the confinement region, and beyond some critical threshold the energy buildup causes an instability that gives rise to a loss of energy from the confinement region, resulting in a reduction in total energy (Fig. 8).

Associated with the ETPs are fluctuations of various types, as seen on the SXR array as well as the Mirnov coils. Isolated "m=even" events seen on the SXR often precede an ETP or occur between two ETPs. The $m=e v e n$ events are up-down symmetric, and they originate at the plasma edge and propagate inward with increasing amplitude over a duration of $\sim 0.5 \mathrm{msec}$. The events are characterized by local reductions in the SXR emissivity, but they result in only minimal energy loss $(\leq 1 \%)$. An ETP is actually a series of turbulent $m=$ even events. Fluctuation levels in both the SXR array and Mirnov coils during the ETP are enhanced from 0 to $100 \mathrm{kHz}$ by up to a factor of ten. The SXR data show enhancements everywhere except within the $q=1$ surface, with the maximum relative fluctuation ( $S / S \sim 20 \%$ ) seen near the edge. The magnetic fluctuations during the ETP are enhanced both on the inboard and the outboard coils.

\section{Ion Bernstein Wave Modified H-modes}

The motivations for using Ion Bernstein Wave (IBW) injection in PBX-M are as an additional auxiliary heating source and as a means of controlling the pressure profile through heating of the ions. Experiments indicated that the IBW was indeed successful in heating the ions [19], but, additionally, the IBW yielded another, unexpected result. With IBW powers as low as $<10 \%$ of the total heating power, the density profile was seen to

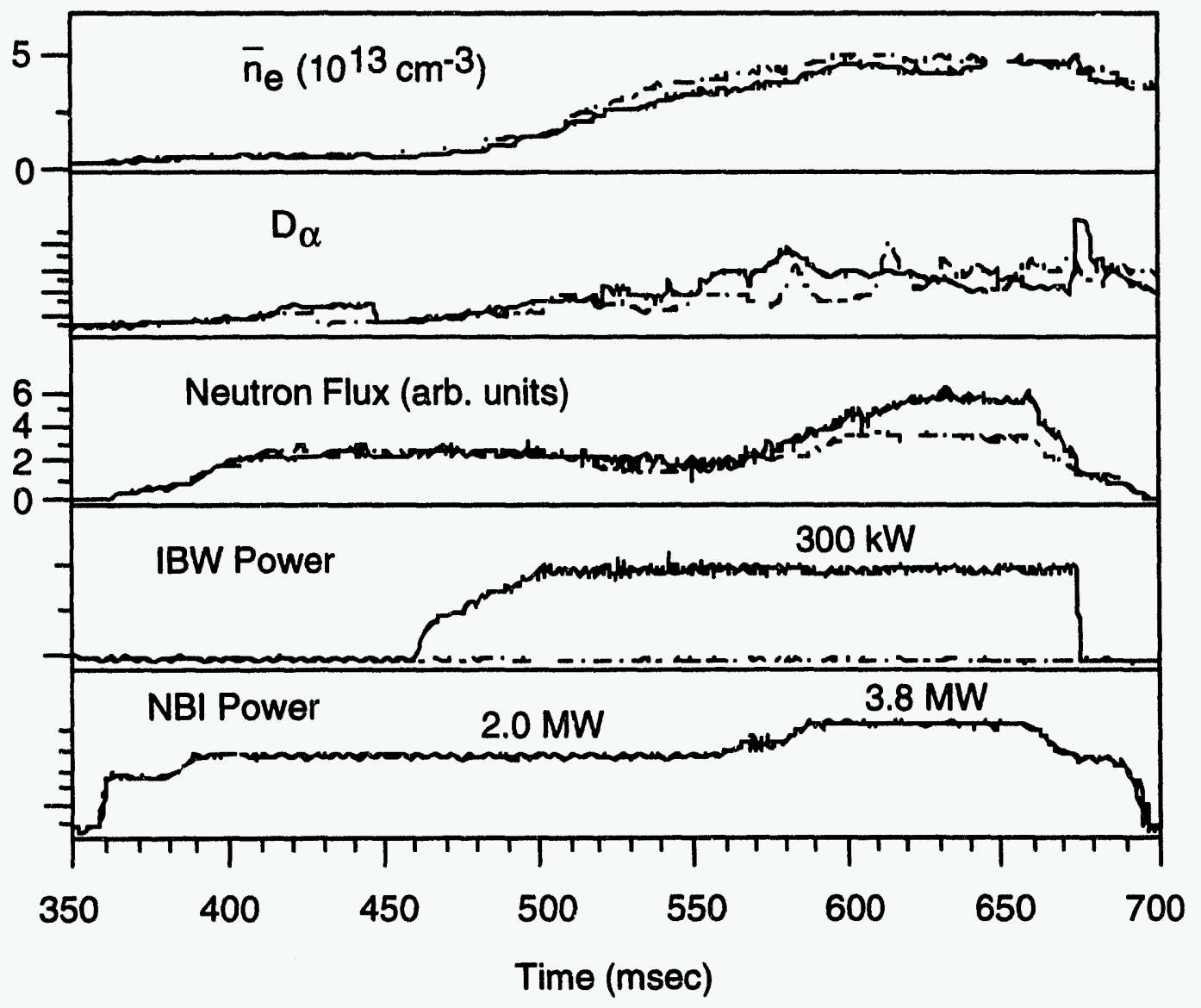

Fig. 9 Comparison of an NBI-only discharge (dashed line) to an NBI+IBW discharge (sold line). 
evolve from its usual state during $\mathrm{OH}, \mathrm{L}$-mode, or $\mathrm{H}$-mode discharges into a peaked profile similar to those obtained in supershots [20] or PEP modes [21]. Similar to supershots and PEP modes, the IBW induced peaked density profiles led to enhanced core confinement, enhanced neutron flux, and, thus, the potential for enhanced reactivity in reactor applications [3].

An overview of an IBW-modified $\mathrm{H}$-mode, and a comparison to a discharge with equivalent neutral beam power but no IBW power is shown in Fig. 9. In both discharges, $2 \mathrm{MW}$ of NBI was applied early ( $-375 \mathrm{msec})$, with an additional $1.8 \mathrm{MW}$ applied approximately $200 \mathrm{msec}$ later. The IBW power was turned on, for one of the discharges, at $\sim 450 \mathrm{msec}$, ramping up to its maximum value of $300 \mathrm{~kW}$ by $500 \mathrm{msec}$. A comparison of the two discharges shows the line integrated density to be practically the same (top trace). The NBI-only discharge transitioned into the H-mode at $425 \mathrm{msec}$, while the NBI+IBW discharge transitioned at $450 \mathrm{msec}$ (before the IBW power was turned on). Both discharges remained in the H-mode for the duration of the NBI (and IBW). The NBI-only discharge exhibited sawtoothing during the H-phase. Not seen in this discharge, but observed in other NBI+IBW discharges, was the appearance of ELMs during the IBW phase after the onset of the density profile peaking, indicating that edge pressure remained high. An important feature of the peaked density $\mathrm{H}$-mode was the increase in the measured neutron flux. As seen in the figure, the neutron flux was approximately $60 \%$ higher in the NBI+IBW discharge than that with NBI alone. This increase in neutrons, it must be stressed again, comes about with only $300 \mathrm{~kW}$ of IBW relative to 3.8 MW of NBI. Lower beam power ( 2.0 MW) discharges also with several hundred $\mathrm{kW}$ of
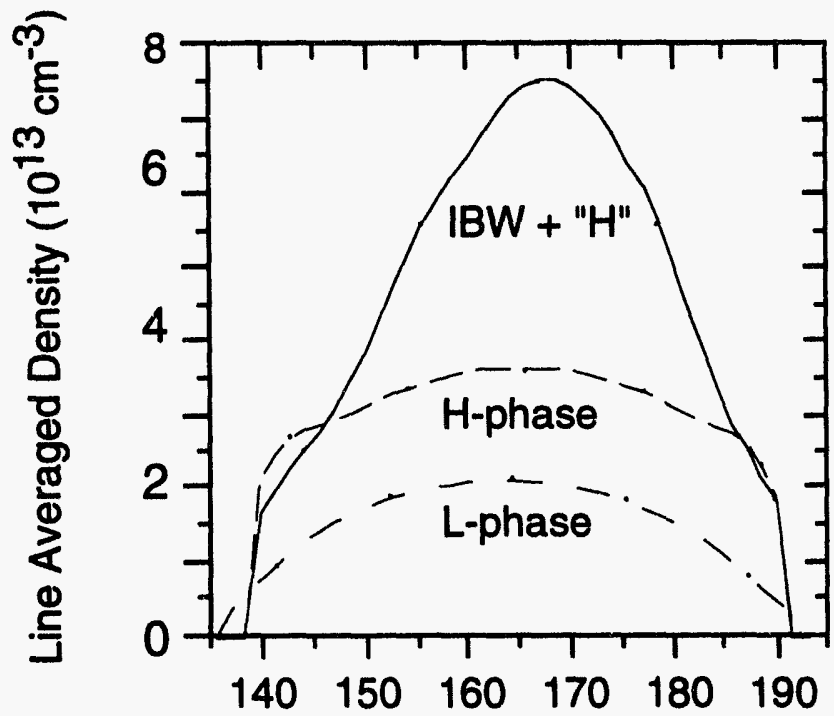

Major Radius (cm)

Fig. 10 Density profiles during the L-, $H-$, and $\mathrm{IBW}+$ "H" phases of a discharge
IBW resulted in comparable relative enhancement in neutron flux over that of a $\sim 2 \mathrm{MW}$ discharge without IBW.

The evolution of the density profile during the NBI+IBW discharge is shown in Fig. 10, where density profiles from the L-, preIBW $\mathrm{H}-$, and during IBW H-phases are plotted. The Hprofile exhibits the usual characteristics of a flattening in the core and a steepening at the edge, relative to the L-phase profile.

After the IBW was injected, the profile peaked up in the center while retaining the steep density gradient and high density near the edge. The edge densities were, however, not as high as those during the $\mathrm{H}$-phase. The large density gradient in the core, near a/2, coincides with the location of the IBW deposition. In most discharges, the edge density decreased to L-mode levels during the course of the IBW. A candidate for explaining the core improvement during IBW is shear stabilization of the core turbulence; the radial 
electric fields necessary for this stabilization can be produced by the ponderomotive force of the deposited IBW waves [22]. Calculations indicate the predicted poloidal velocity shear to be sufficiently localized and of the correct magnitude $\left(>5 \times 10^{5} \mathrm{sec}^{-1}\right)$ to suppress the core fluctuations [3].

\section{Conclusions}

Experiments on PBX-M have yielded information on a wide range of detailed physics aspects of the $\mathrm{H}$-mode, from the transition to well into the $\mathrm{H}$-phase. A unique divertor biasing scheme has led to transition power threshold reductions of $25 \%$.

Magnetic fluctuations, while generally decreasing going from $\mathrm{L}-$ to $\mathrm{H}-$, cannot be used to predict the occurrence of a transition. Turbulent transport decreases going from L- to $\mathrm{H}$-, but the reduction in turbulence is only partially responsible for the transport decrease; the narrowing of the turbulent spectra and the decrease in the correlation between the density and potential fluctuations are also crucial elements. An important feature during the $\mathrm{H}$ phase, ELMs, show a complicated evolution involving high frequency activity before the $\mathrm{D}_{\alpha}$ rise, and harmonic activity, that may be linked to kinetic ballooning modes, appearing coincident with the $D_{\alpha}$ increase. Longer period energy loss phenomena, ETPs, are also observed. Finally, low levels of IBW power injected into $\mathrm{H}$-modes give rise to discharges that combine the improved edge confinement of the $\mathrm{H}$-mode with improved core confinement, the latter producing peaked density profiles that are of potential use in reactor applications.

\section{Acknowledgments}

The work was supported by U.S. Department of Energy Contract No. DE-AC02-76CHO3073 at PPPL, DE-AC05-84OR21400 at ORNL, and DE-FG-89ER51121 at UCLA.

\section{References}

1] N.R. Sauthoff et al., in Plasma Physics and Controlled Nuclear Fusion Research 1 (1991) 709.

2] S.M. Kaye et al., Nuc. Fusion 30 (1990) 2621.

3] B. LeBlanc et al., to appear in Phys. Fluids B (1994).

4] J. Christiansen et al., Nuc. Fusion 32 (1992) 291.

5] F. Ryter et al., Nuc. Fusion $\underline{33}$ (1993) 979.

6] S.M. Kaye et al., this conference.

7] L. Schmitz et al., in Proc IAEA Tech. Comm. Mtg. on Tokamak Biasing, Montreal (1992) in press.

8] F. Ryter et al., in Controlled Fusion and Plasma Physics, Proc. of $20^{\text {th }}$ Eur. Conf., Lisbon, Vol. 17C, (1993) 15.

9] G. Tynan et al., this conference.

10] R. Groebner, Phys. Fluids B 5 (1993) 2343.

11] H. Biglari et al., Phys. Fluids B 2 (1990) 1.

12] F. Wagner et al. in Ref. 1, Vol. 1, 473.

13] DIII-D Team in Ref. 1, Vol. 1, p. 69.

14] P.R. Thomas, in Controlled Fusion and Plasma Physics, Proc. of $19^{\text {th }}$ Eur. Conf., Innsbruck, Vol. 16C, (1992) 239.

15] D. Schissel et al. in Ref. 12, Vol. 16C, p. 235.

16] H. Biglari and L. Chen, Phys. Rev. Lett. 67 (1991) 3681.

17] S.T. Tsai and L. Chen, Phys. Fluids B 5 (1993) 3284.

18] S. Sesnic, this conference. 
19] W. Tighe et al., in Controlled Fusion and Plasma Physics, Proc. of $20^{\text {th }}$ Eur. Conf., Lisbon, Vol. 17C (1993) 969.

20] J. D. Strachan et al., Phys. Rev. Lett. 58 (1987) 1004.

21] The JET Team, in Plasma Physics and Cont. Nuc. Fusion Research 1 (1989) 215.

22] H. Biglari et al., in Radio Frequency Power in Plasmas, Am. Inst. Physics, N.Y.

(1991) 376. 


\section{EXTERNAL DISTRIBUTION IN ADDITION TO UC-420}

Dr. F. Paoloni, Univ. of Wollongong, AUSTRALIA

Prof. M.H. Brennan, Univ. of Sydney, AUSTRALIA

Plasma Research Lab., Australian Nat. Univ., AUSTRALIA

Prof. I.R. Jones, Flinders Univ, AUSTRALIA

Prof. F. Cap, Inst. for Theoretical Physics, AUSTRIA

Prof. M. Heindler, Insutut für Theoretische Physik, AUSTRIA

Prof. M. Goossens, Astronomisch Instituut, BELGIUM

Ecole Royale Militaire, Lab. de Phy. Plasmas, BELGIUM

Commission-European, DG. XII-Fusion Prog., BELGIUM

Prof. R. Bouciqué, Rijksuniversiteit Gent, BELGIUM

Dr. P.H. Sakanaka, Instituto Fisica, BRAZIL

Prof. Dr. I.C. Nascimento, Instituto Fisica, Sao Paulo, BRAZIL Instituto Nacional De Pesquisas Espaciais-INPE, BRAZIL

Documents Office, Atomic Energy of Canada Lid., CANADA

Ms. M. Morin, CCFMTokamak de Varennes, CANADA

Dr. M.P. Bachynski, MPB Technologies, Inc., CANADA

Dr. H.M. Skarsgard, Univ. of Saskatchowan, CANADA

Prof. J. Teichmann, Univ. of Montreal, CANADA

Prof. S.R. Sreonivasan, Univ. of Calgary, CANADA

Prof. T.W. Johnston, INRS-Energie, CANADA

Dr. R. Bolton, Centre canadien de fusion magnétique, CANADA

Dr. C.R. James, Univ. of Alberta, CANADA

Dr. P. Lukác, Komenského Universzita, CZECHO-SLOVAKIA

The Librarian, Culham Laboratory, ENGLAND

Library, R61, Rutherford Appleton Laboratory, ENGLAND

Mrs. S.A. Hutchinson, JET Library, ENGLAND

Dr. S.C. Sharma, Univ. of South Pacific, FIJI ISLANDS

P. Măhönen, Univ. of Helsinki, FINLAND

Prot. M.N. Bussac, Ecole Polytechnique, FRANCE

C. Mouttet, Lab. de Physique des Milieux lonisés, FRANCE

J. Radet, CEN/CADARACHE - Bat 506, FRANCE

Prof. E. Economou, Univ. of Crete, GREECE

Ms. C. Rinni, Univ. of loannina, GREECE

Preprint Library, Hungarian Academy of Sci., HUNGARY

Dr. B. DasGupta, Saha Inst of Nuclear Physics, INDIA

Dr. P. Kaw, Inst. for Plasma Research, INDIA

Dr. P. Rosenau, Israel Inst of Technology, ISRAEL

Librarian, Intemational Center for Theo Physics, ITALY

Miss C. De Palo, Associazione EURATOM-ENEA, ITALY

Dr. G. Grosso, Istituto di Fisica del Plasma, ITALY

Prof. G. Rostangni, Istituto Gas lonizzati Del Cnr, ITALY
Dr. H. Yamato, Toshiba Res \& Devel Center, JAPAN

Prof. I. Kawakami, Hiroshima Univ., JAPAN

Prof. K. Nishikawa, Hiroshima Univ., JAPAN

Librarian, Naka Fusion Research Establishment, JAERI, JAPAN

Director, Japan Atomic Energy Research Inst., JAPAN

Prof. S. Itoh, Kyushu Univ., JAPAN

Research Info. Ctr., National Instit. for Fusion Science, JAPAN

Prof. S. Tanaka, Kyoto Univ., JAPAN

Library, Kyoto Univ., JAPAN

Prof. N. Inove, Univ. of Tokyo, JAPAN

Secretary, Plasma Section, Electrotechnical Lab., JAPAN

S. Mori, Technical Advisor, JAERI, JAPAN

Dr. O. Mitarai, Kumamoto Inst. of Technology, JAPAN

Dr. G.S. Loe, Korea Basic Sci. Ctr., KOREA

J. Hyeon-Sook, Korea Atomic Energy Research Inst., KOREA

D.I. Choi, The Korea Adv. Inst. of Sci. \& Tech., KOREA

Prof. B.S. Liley, Univ. of Waikato, NEW ZEALAND

Inst of Physics, Chinese Acad Sci PEOPLE'S REP. OF CHINA.

Library, Inst. of Plasma Physics, PEOPLE'S REP. OF CHINA

Tsinghua Univ. Library, PEOPLE'S REPUBLIC OF CHINA

2. Li, S.W. Inst Physios, PEOPLE'S REPUBLIC OF CHINA

Prof. J.A.C. Cabral, Instituto Superior Tecnico, PORTUGAL

Prof. M.A. Hellberg, Univ. of Natal, S. AFRICA

Prof. D.E. Kim, Pohang Inst. of Sci. \& Tech., SO. KOREA

Prof. C.I.E.M.A.T, Fusion Division Library, SPAIN

Dr. L. Stenflo, Univ. of UMEA, SWEDEN

Library, Royal Inst. of Technology, SWEDEN

Prof. H. Wilhelmson, Chalmers Univ of Tech., SWEDEN

Centre Phys. Des Plasmas, Ecole Polytech, SWITZERLAND

Bibliotheek, Inst. Voor Plasma-Fysica, THE NETHERLANDS

Asst. Prot. Dr. S. Cakir, Middle East Tech. Univ., TURKEY

Dr. V.A. Glukhikh,Sci. Res. Inst. Electrophys.I Apparatus, USSR

Dr. D.D. Ryutov, Siberian Branch of Academy of Sai., USSR

Dr. G.A. Eliseev, I.V. Kurchatov Inst., USSR

Librarian, The Ukr.SSR Academy of Sciences, USSR

Dr. L.M. Kovrizhnykh, Inst. of General Physics, USSR

Kemforschungsanlage GmbH, Zentralbibliothek, W. GERMANY

Bibliothek, Inst. Für Plasmaforschung, W. GERMANY

Prof. K. Schindler, Ruhr-Universitát Bochum, W. GERMANY

Dr. F. Wagner, (ASDEX), Max-Planck-Institut, W. GERMANY

Librarian, Max-Planck-Institut, W. GERMANY 

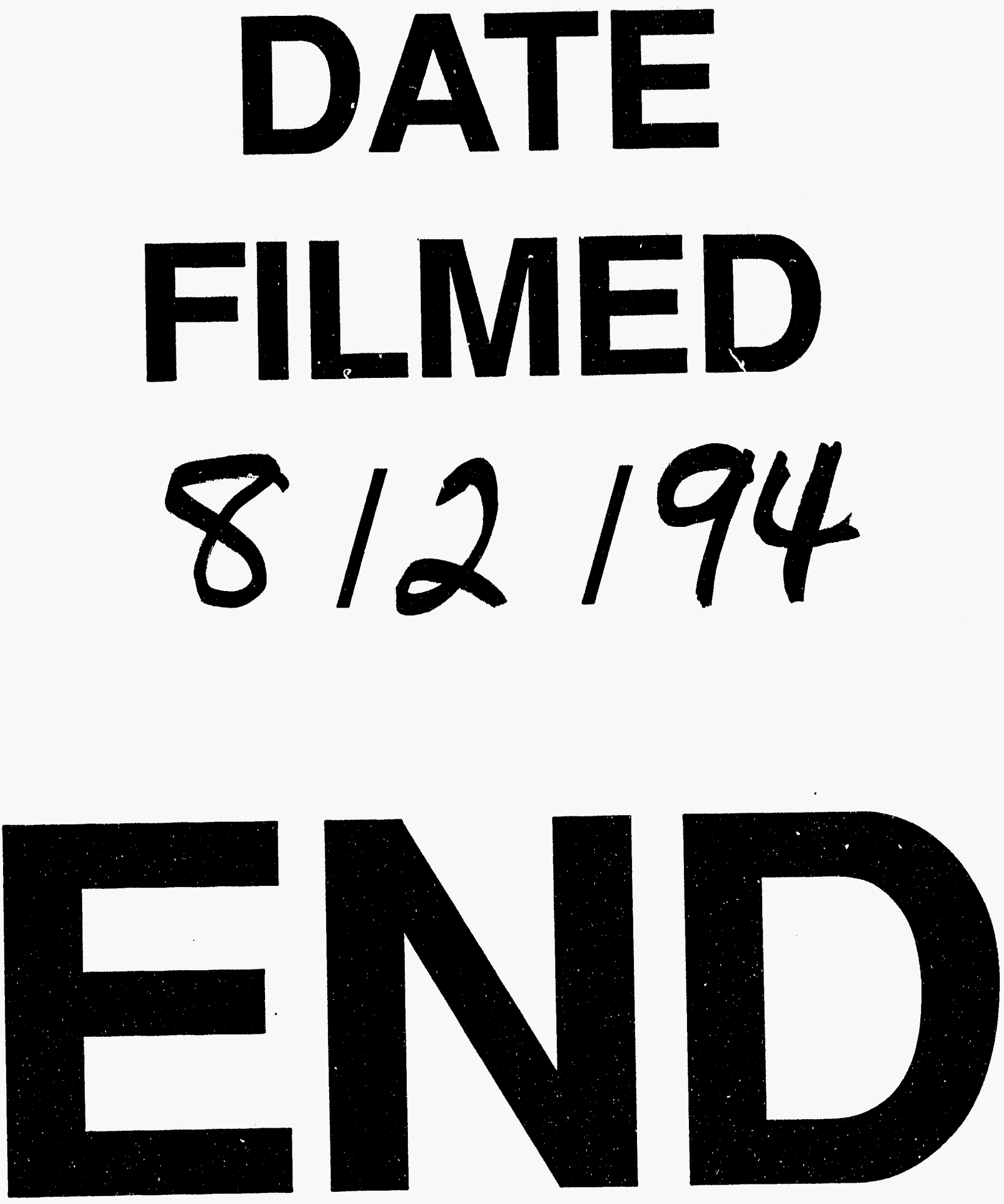
